\title{
Studi Eksperimental Pengaruh Variasi Diameter Tabung Ear Resonator terhadap Tekanan Aliran Udara Supercharging pada Inlet Manifold
}

\author{
Fany Laamena*, Abdul Hadi, Frits Noya, Mario Letsoin
}

Jurusan Teknik Mesin, Fakultas Teknik, Universitas Pattimura

Jl. Ir. M. Putuhena, Poka - Ambon 97234

*E-mail: fanylaamena@fatek.unpatti.ac.id

Diterima: 18-03-2021; Direvisi: 31-03-2021; Dipublikasi: 27-04-2021

\begin{abstract}
Abstrak
Supercharger dan resonator merupakan komponen penting menyangkut tekanan udara pada langkah pembakaran dalam motor diesel 4 tak. Penelitian ini bertujuan untuk mengetahui pengaruh diameter tabung Ear Resonator terhadap tekanan aliran udara Supercharging pada Inlet Manifold. Metode eksperimental digunakan dalam penelitian dengan memvariasikan diameter tabung sebanyak 5 buah Ear Resonator yaitu 1/2", 3/4", 1", 11/4", dan 11/2" yang dipasang secara horizontal. Hasil olahan selisih rata-rata tekanan input dan output menyatakan bahwa variasi diameter tabung Ear Resonator berpengaruh terhadap tekanan yaitu: Variasi ke-2 merupakan tekanan output tertinggi dengan nilai sebesar $101359.90 \mathrm{~N} / \mathrm{m}^{2}$ atau dengan beda tekanan output dan input dengan nilai sebesar $-64.92 \mathrm{~N} / \mathrm{m} 2$ atau sebesar $-0.06 \%$. Variasi ke-5 merupakan salah satu tekanan output terendah dengan nilai sebesar 101325.04 $\mathrm{N} / \mathrm{m} 2$ atau dengan beda tekanan output dan input tertinggi dengan nilai sebesar $23.31 \mathrm{~N} / \mathrm{m}^{2}$ atau sebesar $0.02 \%$.
\end{abstract}

Kata kunci: ear resonator; inlet manifold; tekanan

\begin{abstract}
The supercharger and resonator of the important components regarding the air pressure in the combustion step in a 4 stroke diesel engine. This study aims to determine the effect of the diameter of the Ear Resonator tube on the supercharging air flow pressure at the Inlet Manifold. The experimental method was used in the study by varying the diameter of the tube as many as 5 Ear Resonators, namely 1/2 ", 3/4", 1 ", 11/4", and 11/2 "which were installed horizontally. The processing result of the difference in the average input and output pressure states that the variation in the diameter of the Ear Resonator tube has an effect on pressure, namely: The 2nd variation is the highest output pressure with a value of $101359.90 \mathrm{~N} / \mathrm{m}^{2}$ or with a difference in output and input pressure with a value of $-64.92 \mathrm{~N} /$ $\mathrm{m}^{2}$ or $-0.06 \%$. The 5 th variation is one of the lowest output pressures with a value of $101325.04 \mathrm{~N} / \mathrm{m}^{2}$ or with the highest difference in output and input pressure with a value of $23.31 \mathrm{~N} / \mathrm{m}^{2}$ or $0.02 \%$.
\end{abstract}

Keywords: ear resonator; inlet manifold; tekanan

\section{Pendahuluan}

Sistem bahan bakar merupakan salah satu sistem yang mengalami kemajuan teknologi yang pesat dimana mesin menggunakan prinsip kerja 4 langkah yang menurut prosedurnya mempunyai beberapa keuntungan di antaranya menyempurnakan atomisasi, distribusi bahan bakar yang lebih baik, lebih irit, emisi gas buang rendah, dan tenaga mesin meningkat. Keuntungan tersebut dipengaruhi oleh beberapa faktor, salah satunya adalah efisiensi ruang bakar yang ditentukan oleh besarnya suplai udara yang masuk dan untuk mendapatkannya, maka diperlukan komponenkomponen tambahan berupa supercharging dan resonator.

Petrovsky [7] mengatakan pada ada langkah pembakaran dalam motor diesel 4 tak, sangat dibutuhkan temperature dan tekanan yang tinggi untuk mencapai titik nyala api sehingga terjadi pembakaran sempurna. Dalam hal ini, Supercharger dan tabung ear resonator memiliki peranan yang penting menyangkut tekanan udara. Proses pengaplikasian resonator pada mesin digunakan berbagai variasi resonator pada inlet manifold antara lain helmholtz resonator yang diteliti oleh Hersch dan Walker [2] mengenai pengontrolan kondisi aliran, sedangkan Daniele Bortoluzzi, et. al. [1] dalam penelitiannaya mengenai efek dari penggunaan resonator yang bisa diseting terhadap 
efisiensi volumetrik dari sebuah mesin dan Dupère [3] dalam hasil penelitiannya menuliskan bahwa salah satu cara untuk mengontrol ketidakstabilan pembakaran adalah dengan mengatur leher ear resonator Helmholtz. Yuanita.F.A, dkk [15] meneliti tentang pengaruh diameter leher resonator Helmholtz pada alat pemanen energi akustik terhadap daya listrik yang dihasilkan dan menyimpulkan bahwa diameter leher yang semakin besar menghasilkan daya listrik yang semakin besar.

Semua upaya dilakukan untuk memberikan hasil yang sempurna dalam proses pembakaran dalam mesin. Itulah sebabnya penelitian ini mencoba memvariasikan diameter tabung ear resonator dengan tujuan untuk mendapatkan diameter terbaik yang menghasilkan tekanan aliran udara terbesar pada supercharging pada inlet manifold yang sangat berguna dalam proses pembakaran mesin.

\section{Material dan metodologi}

\subsection{Konsep dan Persamaan Dasar}

Resonator memiliki peran yang sangat penting. Dalam Penelitian yang dilakukan oleh Daniele Bortoluzzi, dkk. [2] menunjukan bahwa efek dari resonator terhadap efisiensi volumetrik sebuah mesin dapat mengalami peningkatan dengan melakukan variasi penyetelan terhadap resonator. Fenomena akustik yang berada pada intake system sangat mempengaruhi efisiensi volumetrik dari mesin. Variasi resonator membuat mungkin untuk mengeksploitasi getaran akustik untuk berbagai frekuensi piston dengan cara yang terbaik. Hasil terbaik diperoleh ketika resonator dengan volume variabel ditempatkan seri dekat silinder dan ketika resonator sisi cabang dengan penampang variabel terhubung ke resonator volume konstan.

Potul, dkk. [9] menerangkan bahwa dengan penggunaan helmholtz resonator dapat mengirim gelombang tekanan tepat tiba pada saat inlet valve terbuka dengan melakukan penyesuaian terhadap variasi panjang intake manifold. Gelombang tekanan yang dikirim dapat meningkatkan efisiensi volumetrik mesin sehingga terjadi juga peningkatan di torsi dan performa mesin. Selain itu, Wan dan Soedel [14], menyimpulkan bahwa pendekatan yang disajikan untuk sistem dua-DOF dapat memprediksi dengan benar frekuensi resonansi dari resonator Helmoltz secara umum.

Menurut Hanriot [5], aliran berdenyut yang terjadi di intake manifold mesin berasal dari gerakan periodik dari katup intake dan dari perbedaan tekanan antara atmosfer dan silinder. Aliran berdenyut dapat meningkatkan atau menurunkan laju aliran massa udara ke dalam silinder. Amplitudo gelombang dilemahkan oleh pantulan dalam pipa dan oleh efek gesekan. Tingkat aliran massa maksimum dan minimum yang terkait dengan fase gelombang yang tiba di katup intake. Resonator yang ditempatkan di dekat katup dapat meningkatkan aliran massa pada frekuensi resonansi. Semakin dekat resonator dengan katup, semakin tinggi tingkat aliran massa udara intake mesin. Posisi resonator mengubah mekanisme dasar dinamika aliran yang dihasilkan dari aliran alami yang tak stabil dan periodik dari proses intake.

\section{Supercharger}

Supercharger mirip dengan turbocharger, tetapi turbocharger ditenagai oleh arus gas keluaran mesin (exhaust) yang mendorong turbin. Supercharger dapat menyerap sebanyak sepertiga tenaga crankshaft mesin dan dalam banyak aplikasi kurang efisien daripada turbocharger. Merle dan David [8] menulis tentang daya dihasilkan ketika campuran udara dan bahan bakar, dibakar di dalam sebuah silinder mesin. Jika udara dipaksa lebih banyak ke dalam silinder, maka bahan bakar akan lebih banyak yang akan terbakar. Dalam penerapannya di mana tenaga atau daya yang besar 
lebih penting dari pertimbangan lain, seperti dragster top fuel dan kendaraan yang digunakan dalam kompetisi tractor pull, supercharger sangat umum digunakan.

\section{Ear resonator}

Ear resonator adalah salah satu resonator dari berbagai resonator yang ada. Ear resonator memiliki fungsi yang sama dengan resonator pada umumnya, yang ditulis oleh Everest [4] yaitu menghasilkan resonansi dan juga meredam suara. Ia juga mengatakan fungsinya secara khusus adalah memberikan gelombang tekanan sehingga ketika sampai ke inlet manifold dapat mempengaruhi tekanan input menjadi lebih tinggi agar efisiensi volumetrik mesin meningkat. Nudehi dkk. [12], menunjukkan bahwa karakteristik attenuation Resonator Helmholtz dapat ditingkatkan dengan mengganti ujung pelat resonator yang kaku dengan yang fleksibel. Resonator dimodifikasi sehingga menghasilkan besarnya redaman pada frekuensi. Ear resonator memiliki dua buah inlet pipa kapiler dengan sebuah tabung yang divariasikan diameternya agar sesuai dengan kebutuhan frekuensi yang diinginkan. Sehingga aliran udara yang ada dalam tabung ear resonator juga akan menjadi lebih dinamis.

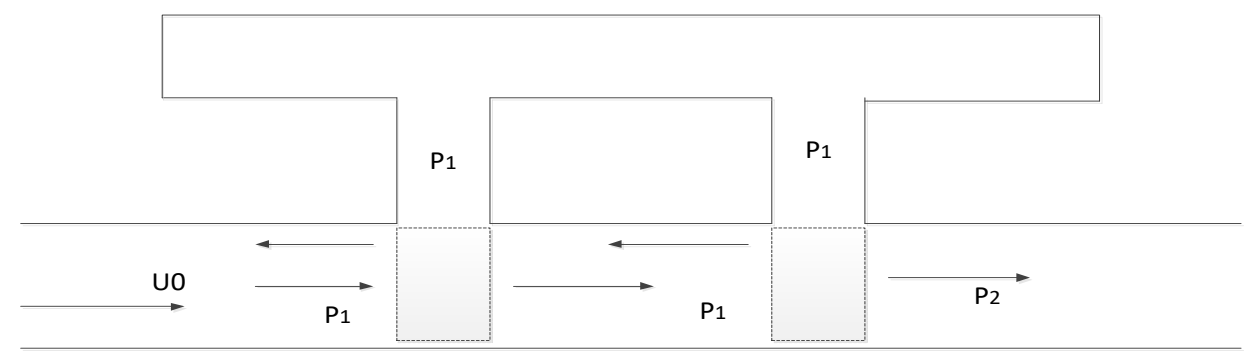

Gambar 1. Aliran dan tekanan dalam ear resonator [13]

Menurut Xiaofeng [13], pada Gambar 1, resonator sisi cabang dipasang pada sisi dinding dari saluran jauh dan gelombang pesawat menjalar sepanjang saluran. Dengan daerah penampang saluran adalah $\mathrm{V}$, maka yang mengalir dalam saluran adalah Uo. Daerah titik menunjukan diskontinuitas tekanan karena aliran rata-rata pada tekanan hulu adalah P1 dan tekanan hilir adalah P2. Tekanan pada leher resonator adalah P3 dan dianggap sama dengan tekanan hulu P1 di persimpangan.

\subsection{Prosedur Penelitian}

Prosedur penelitian sebagai berikut:

1. Mempersiapkan semua perlengkapan dan peralatan yang diperlukan.

2. Memotong besi siku menggunakan alat potong besi menjadi beberapa bagian untuk dudukan mesin penggerak, Supercharger dan Aftercooler.

3. Instalasi peralatan sesuai gambar rancangan.

4. Putaran motor listrik sebesar $1350 \mathrm{rpm}$ pada pulley 6 inci diteruskan melalui v-belt ke poros antara dengan pulley 2 inci (kenaikan putaran sebesar 3 kali). Pada poros antara, pulley 4 inci diteruskan melalui v-belt ke supercharger dengan pulley 2 inci (kenaikan putaran sebesar 2 kali). Setelah mengalami kehilangan akibat gesekan dan lainnya, putaran pada supercharger berkurang menjadi kurang lebih 5000 rpm.

5. Supercharger menarik udara luar masuk menuju aftercooler. Melalui rongga pada aftercooler suhu udara diturunkan dan menuju ear resonator. 
6. Pastikan alat uji berada dalam kondisi telah dikalibrasi dengan baik.

7. Pengambilan data dengan menggunakan Piezo Transducer Sensor.

8. Pemindahan data ke komputer.

9. Pengolahan data dengan menggunakan Program Matlab.

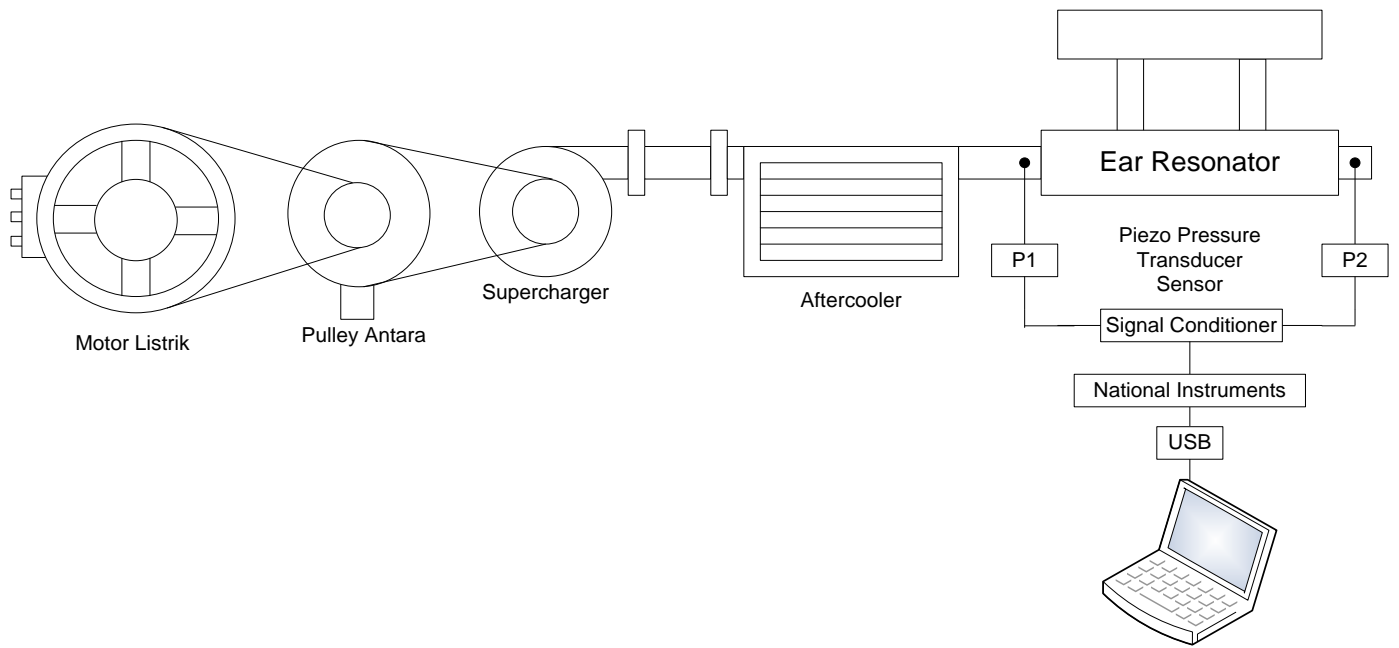

Gambar 1. Instalasi penelitian

\subsection{Metodologi}

Pada penelitian terdahulu, Selamet, A,dkk [11], menggunakkan tiga metode analitis yakni teoritis, komputasi, dan eksperimental untuk mengetahui Pengaruh dimensi rongga spesifik dari resonator Helmholtz. Penelitian dilakukan pada Laboratorium Pengujian Mesin Fakultas Teknik Universitas Pattimura dengan menggunakan metode eksperimental yang diawali dengan mencari referensi tentang penelitian terdahulu yang berkaitan dengan penelitian yang dilakukan, kemudian dibuat instalasi alat dan memvariasikan diameter tabung sebanyak 5 buah Ear Resonator yaitu 1/2”, 3/4”, 1”, 11/4", dan 11/2" yang dipasang secara horizontal. Setelah itu dibuat pengujian dengan variasi yang ada untuk mendapat hasil koreksi akusisi aliran udara dan diolah menggunakan matlab untuk mendapatkan hasil diameter terbaik yang menghasilkan tekanan terbesar. Menggunakan matematika numerik yang dituliskan oleh Quarteroni, Alfio, Riccardo Sacco and Fausto Saleri [10] sebagai acuan dalam perhitungan pada penelitian ini.

\section{Hasil dan pembahasan}

Hasil olahan dengan menggunakan Matlab terhadap fluktuasi tekanan aliran udara input dan output ear resonator sebanyak 48192 data per detik dengan pengulangan sebanyak 10 kali untuk masing-masing input dan output untuk setiap ear resonator yang divariasikan yang dapat dilihat pada Tabel 1 dan Gambar 2 .

Tabel 1. Hasil olahan selisih rata-rata tekanan aliran udara input dan output untuk setiap variasi ear resonator.

\begin{tabular}{ccccc}
\hline $\begin{array}{c}\text { Variasi Ear } \\
\text { Resonator }\end{array}$ & $\begin{array}{c}\text { Rata-rata Tekanan } \\
\text { Input }\left(\mathrm{N} / \mathrm{m}^{2}\right)\end{array}$ & $\begin{array}{c}\text { Rata-rata Tekanan } \\
\text { Output }\left(\mathrm{N} / \mathrm{m}^{2}\right)\end{array}$ & $\begin{array}{c}\text { Rata-rata Beda Tekanan } \\
\text { Output \& Input }\left(\mathrm{N} / \mathrm{m}^{2}\right)\end{array}$ & $\begin{array}{c}\text { Persentasi Tekanan } \\
\text { Output \& Input }(\%)\end{array}$ \\
\hline Variasi 1 & 101351.09 & 101347.46 & -3.63 & $-3.58 \times 10^{-03}$ \\
Variasi 2 & 101424.81 & 101359.90 & -64.92 & -0.06 \\
Variasi 3 & 101387.39 & 101325.02 & -62.38 & -0.06 \\
Variasi 4 & 101320.00 & 101325.71 & 5.71 & 0.01 \\
Variasi 5 & 101301.74 & 101325.04 & 23.31 & 0.02 \\
\hline
\end{tabular}



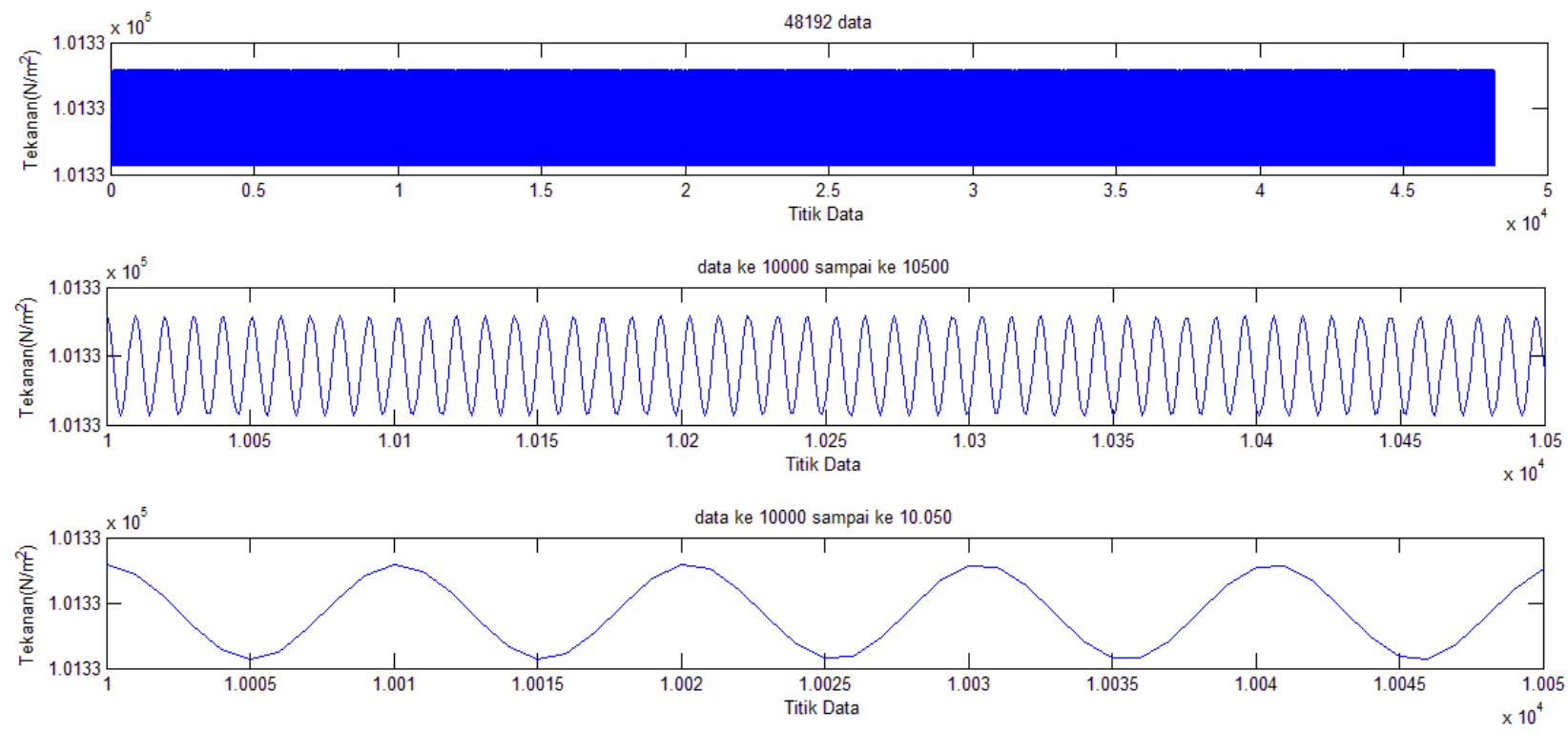

Gambar 2. Grafik tekanan output (Pnout) pada variasi ke-5

Pada grafik pertama dari Gambar 2 dapat dilihat bahwa grafik Pnout tekanan output pada variasi ke-5 sangatlah padat terhadap sumbu $\mathrm{x}$ dan amplitudonya sangat stabil, sehingga menjadi sulit untuk dapat melihat karakteristik dari gelombang tekanan yang ada. Untuk itu pada grafik kedua dan ketiga dari Gambar 4 dibuka skalanya menjadi data ke10000 sampai ke-10500 dan data ke-10000 sampai data ke-10050 agar dapat melihat karakteristik gelombang yang ada.

Hasil tekanan yang didapati sangatlah banyak untuk setiap variasi Ear Resonator yang ada, dikarenakan titik data sebanyak 48192. Untuk itu agar memudahkan melihat amplitudo data dan karakteristik gelombang yang sangat rapat digunakan grafik dengan format semilog terhadap sumbu x dengan nilai 48192 untuk masing masing variasi ear resonator.

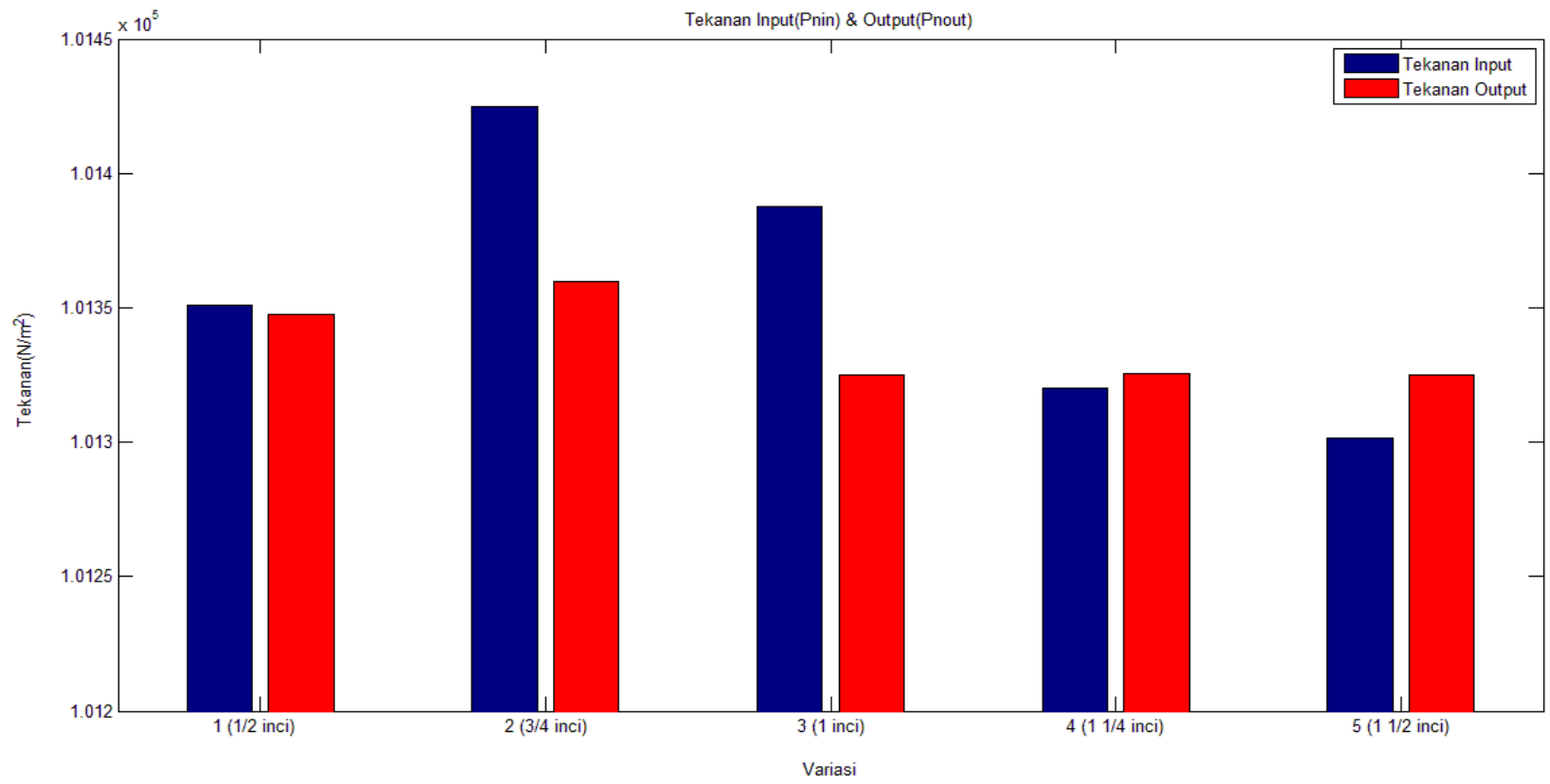

Gambar 3. Grafik diagram batang rata-rata tekanan aliran udara input (Pnin) dan output (Pnout) 
Pada Gambar 3 diambil batas bawah yakni 101200 dan batas atas yakni 101450 dapat dilihat bahwa tekanan ratarata tertinggi input berada pada variasi ke-2 yaitu sebesar $101424.81 \mathrm{~N} / \mathrm{m}^{2}$ yang mana juga merupakan rata-rata tekanan output tertinggi dengan nilai $101359.90 \mathrm{~N} / \mathrm{m}^{2}$. Sedangkan rata-rata tekanan input terendah pada variasi ke-5 sebesar $101301.74 \mathrm{~N} / \mathrm{m}^{2}$ dan rata-rata tekanan output terendah pada variasi ke-3 sebesar $101325.02 \mathrm{~N} / \mathrm{m}^{2}$. Hasil olahan rata-rata tekanan input dan output dibuat grafik selisih rata-rata tekanan (output-input) aliran udara dengan variasi ear resonator pada Gambar 4.

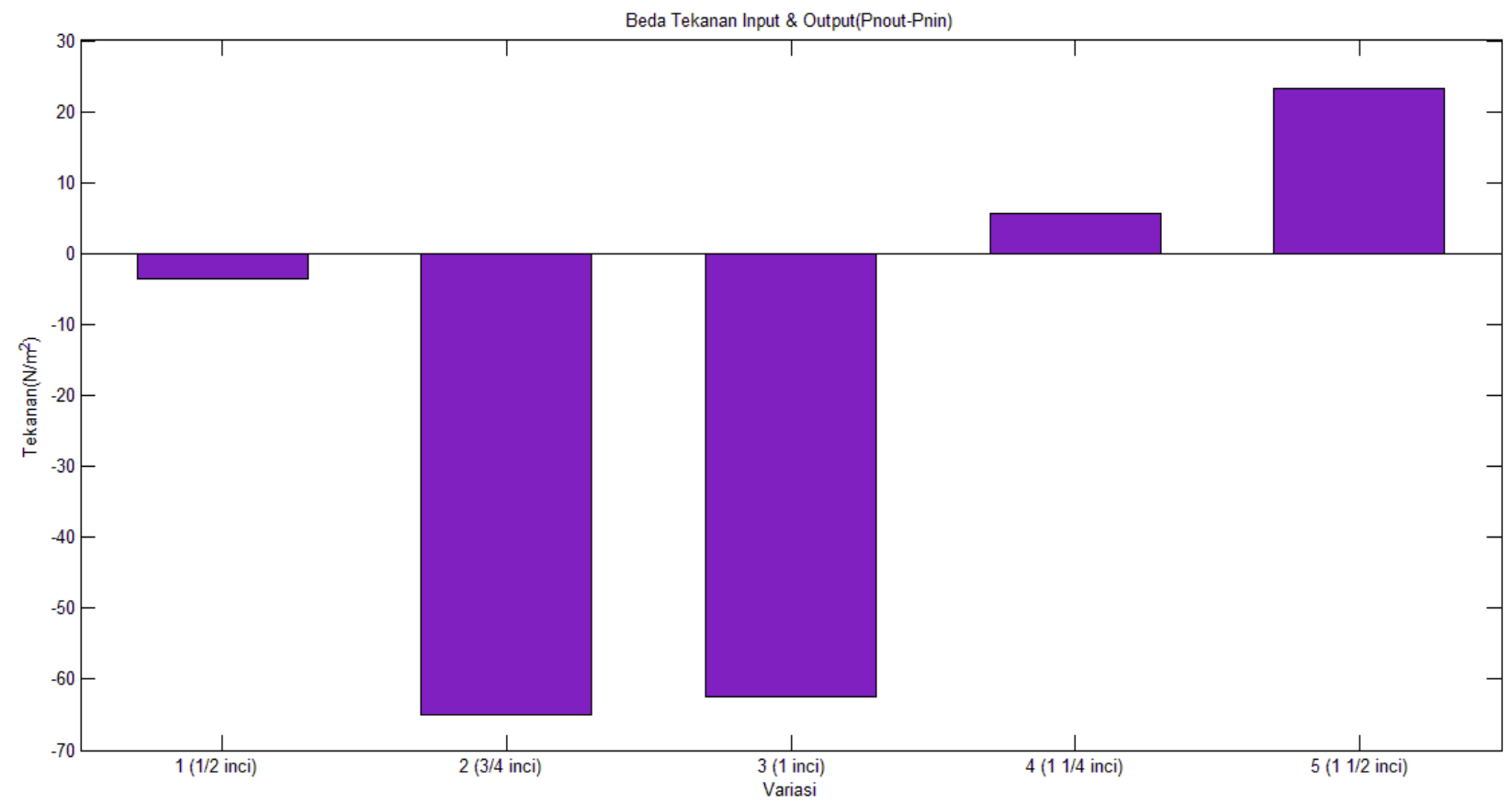

Gambar 4. Grafik diagram batang selisih rata-rata tekanan aliran udara (Pnout-Pnin)

Terlihat bahwa hasil selisih tekanan input dan output mengalami penurunan pada variasi ke-1 sebesar $-3.63 \mathrm{~N} / \mathrm{m}^{2}$, variasi ke-2 sebesar $-64.92 \mathrm{~N} / \mathrm{m}^{2}$, dan variasi ke-3 sebesar $-62.38 \mathrm{~N} / \mathrm{m}^{2}$. Sedangkan hasil selisih tekanan input dan output mengalami kenaikan pada variasi ke-4 sebesar $5.71 \mathrm{~N} / \mathrm{m}^{2}$ dan ke-5 sebesar $23.31 \mathrm{~N} / \mathrm{m}^{2}$. Selisih tekanan input dan output aliran udara ear resonator tertinggi berada pada variasi ke-5 sebesar $23.31 \mathrm{~N} / \mathrm{m}^{2}$ atau sebesar $0,02 \%$ sedangkan pada selisih tekanan input dan output terendah pada variasi ke-2 sebesar $-64.92 \mathrm{~N} / \mathrm{m}^{2}$ atau sebesar $-0.06 \%$.

\section{Kesimpulan}

Berdasarkan hasil dan pembahasan yang telah diurai dapat disimpulkan bahwa Ear Resonator berpengaruh terhadap tekanan keluaran dimana dapat dilihat pada variasi ke-2 dengan beda tekanan output dan input (Pnout-Pnin) terendah dimana barada di bawah 0 atau minus dengan nilai sebesar $-64.92 \mathrm{~N} / \mathrm{m}^{2}$ atau sebesar $-0.06 \%$. Sedangkan pada variasi ke-5 dengan beda tekanan output dan input (Pnout-Pnin) tertinggi dengan nilai sebesar $23.31 \mathrm{~N} / \mathrm{m}^{2}$ atau sebesar $0.02 \%$. Hal ini menunjukan bahwa Ear Resonator lebih efektif bila divariasikan dengan diameter tabung 11/2”, guna untuk meningkatkan tekanan keluaran sebagaimana hasil adanya.

\section{Daftar Pustaka}

[1] Bortoluzzi Daniele, Vittore Cossalter, Alberto Doria. 1998. The Effect of Tunable Resonators on The Volumetric Efficiency of An Engine. SAE technical paper series 98MSE-10 NO. 983045. 
Fany Laamena dkk /Jurnal Rekayasa Mesin

p-ISSN: 1411-6863, e-ISSN: 2540-7678

Vol.16|No.1|116-122|April|2021

[2] Claywell, Mark and Donald Horkheimer. 2006. Improvement of Intake Restrictor Performance for a Formula SAE Race Car through 1D \& Coupled 1D/3D Analysis Methods. SAE 2006-01-3654.

[3] Dupère, I. D. J., and Dowling, A. P. 2005. The Use of Helmholtz Resonators in a Practical Combustor. Journal of Engineering for Gas Turbines and Power, Vol. 127, pp. 268-275.

[4] Everest, F. Alton. 2001. The Master Handbook of Acoustics. Fourth Edition. New York: McGraw-Hill.

[5] Hanriot, S. M, Valle, R.M, Sodré, J.R., and Queiróz, J. M. 2013. Helmholtz Resonator Effects on Engine Intake Air Mass Flow Rate. International Congress of Mechanical Engineering - COBEM 2013, ISSN 2176-5480.

[6] Matko, D., Geiger, G., and Werner, T. 2001. Modelling of the Pipeline as a Lumped Parameter System. Original scientific paper ATKAAF 42(3-4), 177-188 (2001), ISSN 0005-1144.

[7] Petrovsky, Nikolai Viktorovich. 1966. Marine Internal Combustion Engines. MIR Publishers: Moscow. Page: 199201.

[8] Potter C. Merle and Wiggert C. David. 2008. Mekanika Fluida. Penerbit Erlangga, Jakarta.

[9] Potul, Shrinath, Rohan Nachnolkar and Sagar Bhave. 2014. Analysis of Change in Intake Manifold Length and Development of Variable Intake System. Journal of Scientific \& Technology Research Volume 3, Issue 5, ISSN 2277-8616: 223-228.

[10] Quarteroni, Alfio, Riccardo Sacco and Fausto Saleri. 2006. Numerical Mathematics: Second Edition. Springer: Milan

[11] Selamet, A., Dickey, N. S., Radavich, P. M., and Novak, J. M. Theoretical, Computational and Experimental Investigation of Helmholtz Resonators: One-Dimensional Versus Multi-Dimensional Approach. SAE 940612.

[12] Shahin S. Nudehi, G. Scott Duncan and Umar Farooq, Journal of Vibration and Acoustics, Volume 135, ASME.

[13] Shi, Xiaofeng, Cheuk M. Mak, and Jun Yang. 2013. Attenuation Performance of a Semi-Active Resonator in a Grazing Flow Duct. Journal of Acoustics, 3, 25-29

[14] Wan, D., and Soedel, D. T. 2004. Two Degree of Freedom Helmholtz Resonator Analysis. SAE 2004-01-0387.

[15] Yuanita.F.A, dkk, 2019. Pengaruh Diameter Leher Resonator Helmholtz Pada Alat Pemanen Energi Akustik (Acoustic Energy Harvester) Terhadap Daya Listrik Yang Dihasilkan. Prosiding SNFA, E-ISSN: 2548-8325 